\title{
Optimising the Use of Cemented Backfill by Using an Effective Stress Constitutive Model
}

\author{
A. Fourie Australian Centre for Geomechanics, Australia \\ M. Helinski University of Western Australia, Australia \\ M. Fahey University of Western Australia, Australia
}

\begin{abstract}
Cemented backfill is an important contribution to ground support, particularly in high stress conditions. The rate at which strength, and more importantly stiffness, increases with time after placement of backfill is crucial to the safe and reliable use of this technology, but is an area that is currently poorly understood. The importance of the interaction between fill type, binder and water used during the hydration process and their impact on the rate of gain of stiffness and strength is highlighted. The principle of effective stress is critical to understanding how pore pressures generated during placement and consolidation of backfill affects the loads on barricades used to retain the newly-placed fill. Based on laboratory and in-situ experimental work, a constitutive model has recently been developed at the University of Western Australia that considers strength and stiffness gain with hydration time, self-desiccation and the effect on pore pressures in the fill. A comparison of pore pressures developed during the staged filling of a stope is used to illustrate the versatility of the model when incorporated into a finite element package. The utilisation of this model enables the choice of fill and binder combination to be optimised, and provides greater certainty in the use of cemented backfill in high stress conditions.
\end{abstract}

\section{Introduction}

One of the main functions of backfill placed into mined-out voids underground is to provide ground support. This is true of both uncemented and cemented backfill. There are usually other benefits, including the emergence in recent years of the perceived environmental and liability reduction benefits of not storing all the tailings produced by mining above surface.

Backfilling of large voids, such as the stopes, generally requires that some form of binder, usually cement, is added to the tailings to improve the strength of the backfill. Initially, cemented hydraulic fill was used in applications of this type, but increasingly there has been a move to the use of cemented full-plant tailings, also known as cemented paste backfill (CPB). A benefit of using CPB is that higher solids content slurries can be transported. Other benefits are the reduction of fine grained tailings that must be managed in surface impoundments and the fact that classification of the tailings is no longer required. Disadvantages include the high capital cost, the likely need for higher binder contents than hydraulic fill, the requirement for a high degree of control during the preparation and reticulation of the CPB and the perceptions that safety can be compromised. This latter point will be discussed later in the paper, but it is important to flag the issue here, because through an improved understanding of the fundamentals of CPB behaviour, the safety issue can be addressed.

Although the shear strength of CPB is a critically important consideration, it may be that concentration has (incorrectly) focussed solely on strength when implementing backfilling. This paper argues that the stiffness of the fill, and the rate at which the stiffness develops with time, is an equally critical parameter.

\section{The use of CPB and concerns that have arisen}

There are an increasing number of mines around the world using CPB, particularly in Canada and Australia (see Grabinsky and Bawden, 2007, and Potvin and Fourie, 2005). Unfortunately there have been a substantial number of problems experienced with the implementation of $\mathrm{CPB}$, with the most concerning of these being the failure of barricades (the term barricade is used to indicate a support structure that allows drainage, as 
distinct from a bulkhead, which is considered impermeable (Grice, 2005)) and the potentially fatal mudrushes that can occur as a consequence. The perception that there is something fundamentally unsafe about the use of CPB exists in some quarters, and this has probably restricted more widespread implementation of the technology. This is unfortunate as the technology holds many potential benefits for the mining industry and, as argued in this paper, through an improved understanding of the mechanics of CPB behaviour, this technology can be used with the same level of safety assurance as any other ground support technology.

\subsection{Uncertainties in the design of barricades}

Barricades are required to resist the pressures applied by hydraulically placed CPB long enough to allow the binder to become fully hydrated. Barricades are not required to carry a load in perpetuity, but for a critical period of a few days, they must retain the backfill because there is no second line of defence. There have been a number of barricade failures reported (e.g. Grice, 1998 and Yumlu and Guresci, 2007) and, to our knowledge, an even greater number that have never been publicly reported. Many of the reported failures are characterised by discussions of the uncertainty surrounding the loads applied by the backfill. It is not that appropriate design techniques are not available, but all design procedures require accurate definition of what loads are required to be carried.

Helinski et al. (2006) illustrated this point by referring to a hypothetical stope backfilled with cemented full plant tailings. Two extreme conditions were assumed for the calculation of barricade loads. In the first, the material was assumed to behave in an undrained fashion, meaning that no drainage of water from the backfill occurred during placement and thus no consolidation or settlement of the fill occurred either. This clearly represents an extreme condition, although there have been some indications in the literature that this may be close to the expected condition. It means that virtually the full hydrostatic head of tailings must be retained by the barricade, resulting in large barricade loads and therefore substantial, and costly, barricade structures. The other extreme condition is when full drainage of interstitial water occurs (which does not mean the fill becomes completely dry, but rather that no further gravity drainage of the pore water can occur), resulting in substantial consolidation of the fill mass. As discussed by Fourie et al. (2007), consolidation of the fill mass adjacent to the intact rock walls is resisted by friction developed at this interface. This results in less vertical stress being transferred to the bottom of the stope than would otherwise occur, resulting in the development of 'arching' within the fill mass. Arching thus reduces the amount of load transferred to not only the base of the stope, but also to the barricade. As shown by Helinski et al. (2006), the development of interface friction (and thus arching) is directly related to not only the strength between the fill and the rock, but also to the stiffness of the fill adjacent to the interface. If, for example, the fill is extremely soft and compressible possibly because hydration of the binder has occurred extremely slowly - consolidation can occur with minimal development of friction at the interface and thus minimal arching. As demonstrated by Helinski et al. (2006) in their hypothetical example, the fully drained condition, in which arching occurs, provides a much reduced value of the barricade load, being approximately one order of magnitude less than the prediction obtained from the undrained case.

Barricade loads are often calculated using either the approach of Marston (1930) or Terzaghi (1943). Both these techniques implicitly assume that arching is fully developed in a filled stope, resulting in barricade loads that are substantially lower than hydrostatic values. Using the same material properties as used in the study by Helinski et al. (2006) mentioned above, the predicted barricade stress according to Marston was about $230 \mathrm{kPa}$, which is much less than the value that would be predicted from an undrained analysis, indicating the implicit assumption that the material behaves in a drained manner. According to the Terzaghi approach, zero barricade stresses are developed once the apparent cohesion exceeds $100 \mathrm{kPa}$, because the material becomes self-supporting. The dilemma of using conventional approaches such as those mentioned here is therefore evident.

\subsection{Uncertainties in the definition of appropriate UCS value for use in design}

There are a number of reports of discrepancies between UCS values derived from tests on laboratory specimens and those derived from tests on specimens recovered from full-scale stopes. Explanations for these discrepancies are many and varied, none of them being totally convincing. It seems that factors such as differences in humidity, curing temperature and method of testing all play a part, but there also appears to be 
one major factor that is usually overlooked. This is the differences in curing regime, particularly the fact that material in a stope will be cured under the application of a reasonably high applied load, whereas laboratory specimens are cured in a stress-free environment. It is not only the UCS that can be affected by the curing procedure used, but also the stiffness of the material. As this factor is critically important in the calculation of barricade loads, correct sample preparation and testing is once again critical.

\subsection{Potential liquefaction of backfill}

The potential for liquefaction of CPB may also restrict more widespread application. Although there are discussions of liquefaction of paste fill in the literature (e.g. Been et al., 2002), the unique circumstances of these failures render them essentially isolated incidents. There have also arisen rules of thumb regarding liquefaction susceptibility, such as a minimum UCS of $100 \mathrm{kPa}$ will prevent liquefaction. In the authors' opinion, this rule has not been rigorously tested and may therefore be inappropriate. A more thorough understanding of the fundamental aspects of $\mathrm{CPB}$ behaviour, including the effect of time, is required.

\section{Improving our predictive capability - getting the fundamentals right}

Approaches to the design of CPB systems have tended to evolve from those used in the hydraulic backfill industry, which in turn developed from an approach grounded in concepts of 'total stress'. In this approach, the stresses acting on a CPB material are evaluated as though the material were made of a uniform and consistent matrix and ignores the possibility that different stresses may exist within the pore fluid and within the solid particle framework. Conventional soil mechanics theories of stress distribution within a loaded mass are predicated on drawing exactly this distinction, i.e. under virtually all conditions the total applied stress, $\sigma$, (such as the weight of overburden in a filled stope) is apportioned between two components, the interparticle contact stresses, known as the effective stress $\left(\sigma^{\prime}\right)$ and the stress carried by the pore fluid, usually referred to as the pore water pressure, $u$. In its simplest form this equation is:

$$
\sigma=\sigma^{\prime}+u
$$

The apparent simplicity of this equation can be misleading, because it inevitably needs to be formulated in terms of three dimensional stress invariants for use in numerical modelling, but for purposes of discussion here it is appropriate to present it in its simplest form.

When a saturated mass is first loaded (such as an element of CPB at the base of a stope in which filling recommences after a short break), the increment in load will be carried solely by the pore water, resulting in an increase in this water pressure. The CPB matrix will not experience any increase in load initially. This is because the pore water is much less compressible (has a much higher bulk modulus) than the CPB matrix and therefore preferentially carries the load increment. As water drains from the CPB pores, the matrix can compress and begins to carry some of the load increment. In this way, load transfers from the pore water to the CPB matrix, and the CPB undergoes a decrease in volume, a process known as consolidation. The rate at which consolidation occurs dictates the rate of transfer of stress to the CPB matrix, i.e. the development of effective stress. If this rate of consolidation is too low, virtually no compression of the matrix will occur during the filling of a stope, no development of effective stresses will occur and thus no stress transfer, or arching to the rockwalls will develop. The highest possible barricade loads result under these conditions, which are termed undrained for the reasons outlined above.

The limiting value of shear stress that may be generated at the interface between a fill and the adjacent rock is governed by the shear strength of this interface. Mobilisation of the shear strength requires a certain amount of strain is developed at the interface, and prior to the available strength being mobilised, stress transfer to the rock mass still occurs due to development of elastic strains. During elastic loading, the distribution of stress will occur according to the relative values of stiffness, i.e. the ratio between the vertical compressive stiffness and the shear stiffness. The shear stress $(\tau)$ required to generate stress transfer to the surrounding rock mass can only be generated if the material undergoes a shear strain $(\gamma)$. The mobilised shear stress under these conditions is given by:

$$
\tau=G \gamma
$$


where $\mathrm{G}$ is the shear stiffness of the material. If a fill is loaded undrained, the compressive stiffness is governed by the bulk modulus of water rather than that of the fill skeleton (as explained above), which is about $2 \mathrm{GPa}$. In comparison, the bulk modulus of a fully hydrated CPB is of the order of $40 \mathrm{MPa}$ (and less during hydration), so it will carry no load under undrained conditions. When the fill is loaded undrained, there can be no vertical compression and therefore no induced shear strain. Without shear strain, there can be no development of shear stress (according to the equation above) and hence no stress transfer to the rock walls. As consolidation subsequently occurs, the fill will settle vertically and shear stress will be mobilised at the interface, allowing for some stress transfer to occur.

While a stope is being filled with CPB, some of the material will already be undergoing hydration, which usually begins within four hours after mixing the binder, aggregate and water. As the fill hydrates and bonds begin to develop between particles, the stiffness of the CPB increases. The rate of shear stiffness development influences the extent of stress transfer to the stope walls. If the fill becomes very stiff, a small amount of settlement will generate large shear stresses at the interface of the fill and the stope wall, quickly developing an arching mechanism within the fill. There are thus a number of layers of complexity in the development of arching within a filled stope. As outlined so far, the rate at which consolidation occurs relative to the rate at which filling occurs is one key factor. Another is the rate at which the stiffness of the fill matrix develops compared with the filling rate. Other factors also impact on the extent to which arching within a stope develops, including the mechanism of self-desiccation that occurs because the hydration process results in a net decrease in total volume of material (see Helinski et al., 2007a) and the potential for compression of already-cured material to experience some damage of young cemented bonds as a consequence of additional load application from newly placed fill.

It is important to account for all these contributing, and sometimes conflicting effects, and the best way to approach this issue was considered to be the development of a rigorous constitutive model based on the sound fundamental principles of effective stress theory. This is described later in the paper.

\section{Factors affecting the rate of stiffness development}

There are a number of factors that will affect the rate at which the stiffness of a cemented fill develops, including the type of binder used, the nature of the fill itself (for example the presence of clay minerals may retard the rate of stiffness development) and curing parameters such as temperature and humidity. To illustrate some of these differences, results presented by Coltrona (2006) have been used. Tests on four different materials were carried out using the addition of $3 \%$ OPC. The shear stiffness development with time was monitored in the hydration cell using bender elements as described by Helinski et al. (2007a). Results are given in Table 1 for the final value of shear modulus, Gmax, and the rate at which it develops. This has been quantified by calculating the ratio of shear modulus developed after 20 and 80 hours to the final value.

Table 1 Rate of development of shear stiffness with time for four different materials, all having $3 \%$ cement added

\begin{tabular}{cccc}
\hline Material & Gmax (MPa) & $(\mathbf{G} / \mathbf{G m a x}) 20$ & $(\mathbf{G} / \mathbf{G m a x}) \mathbf{8 0}$ \\
\hline D1 & 380 & 0.37 & 0.76 \\
D2 & 350 & 0.57 & 0.85 \\
D3 & 370 & 0.27 & 0.65 \\
D4 & 350 & 0.29 & 0.77 \\
\hline
\end{tabular}

The final value of Gmax is similar in all four cases. However, the rate at which the stiffness develops is significantly different. Material D2 is a pastefill, with $7 \%$ particles finer than $2 \mu \mathrm{m}$ and $70 \%$ finer than $10 \mu \mathrm{m}$ and is thus a very fine material. However, these fine particles consist of rockflour, rather than clay minerals. It undergoes a relatively rapid development of stiffness with time, reaching more than $50 \%$ of the ultimate value in only 20 hours. Material D3, which contains $25 \%$ finer than $10 \mu \mathrm{m}$, reached only $27 \%$ of its ultimate 
shear stiffness in the same time. This material contains some clay minerals, including talc and it may be that this is the reason for the retarded rate of stiffness development. This is borne out by the results from tests using material D4, which is a commercial grade kaolin clay (not a backfill material at all, but used for comparison purposes). This shows a similar, and in fact slightly better, rate of stiffness gain than material D3, suggesting that the mineralogy of the backfill material can have a dominant effect on stiffness (and indeed strength) gain with time.

The importance of these results in the present context relates to the generation of barricade loads and how these can be reduced by the development of arching within the backfilled mass. As argued earlier, the stiffer the backfilled mass, the better the development of an arching mechanism. Therefore, although materials D2 and D3 develop very similar ultimate values of shear stiffness, within twenty hours after placement, material D3 will be less than half as stiff as material D2 and a much greater percentage of the overburden weight in a stope filled with D3 material will be transferred to the barricades compared with D2. Alternatively, to ensure barricade loads were similar in both cases, a stope using material D3 would have to be filled slower (at least a factor of two slower) than a similar stope filled with material D2. It is not only rate of stiffness development that influences barricade loads, as factors such as hydraulic conductivity and self-desiccation due to hydration are also extremely important (Helinski et al., 2007a). Nevertheless, the rate of gain of stiffness is a critically important factor in the generation of barricade loads and as illustrated here, it can vary markedly from one material to another.

\section{Development of a constitutive model for cemented backfill}

The simulation of stress development during filling (neglecting the influence of pore pressures) has been undertaken by Rankine et al. (2001) and Belem et al. (2004). However, none of these approaches couple pore pressures and stress development, nor any of the other significant mechanisms associated with filling a stope with cemented tailings-based backfill mentioned above. The version of the constitutive model that has been developed at UWA has to date only been incorporated into two-dimensional (plane strain or axisymmetric) finite element formulations. It will ultimately be extended to three-dimensions, but in many cases the 2-D version can be used to estimate barricade loads in an appropriate manner.

The model is a finite element, fully coupled consolidation model based on the consolidation theory of Biot (1941). It also takes account of the following:

Stiffness: Aspects that can influence the material stiffness include the initial uncemented density, cement hydration, and damage to the cement bonds due to excessive strain.

Strength: This can be influenced by cement hydration as well as destruction of cement bonds due to excessive stress or strain.

Hydraulic conductivity: This can be influenced by material density, particle size distribution and cement hydration.

Self desiccation: This refers to the net water volume change that occurs as a result of the chemical reactions associated with the hydration process (Helinski et al. 2007a).

Another significant characteristic of the model incorporated into Minefill-2D is the progressive rising of the fill surface (at any given rate) during the consolidation / hydration process to represent the accretion of material within the stope. The Mohr-Coulomb yield criterion has been adopted to represent the material strength. This allows for internal yielding, and also for yielding at the interface between the fill mass and the surrounding rock mass.

A non-linear stiffness model has been adopted such that the small strain (or initial tangent) stiffness is used initially, but this stiffness reduces as the stress approaches the yield stress in accordance with the non-linear stiffness function suggested by Fahey and Carter (1993). A strain-softening model has been used such that the cementation is progressively destroyed as the material is strained beyond yield.

The water table is allowed to rise and fall above the fill surface according to volumetric strains and flows through the upper material layer. The elevation of the water table dictates the pore pressures at the surface nodes. Calculations are performed in terms of total water head rather than excess pore pressure. The current version of the model assumes fully saturated conditions throughout the filling process. 
The testing procedure devised to provide input parameters to the model involves a minimum of two tests. These include a "hydration test" and a consolidated drained triaxial test. The hydration test is used to measure the properties relating to stiffness development, hydraulic conductivity and self desiccation. A detailed description of the testing procedures is given by Helinski et al. (2007a) and is not repeated here. It is important to note that the parameters required for the model are relatively easy to obtain and the model does not require a suite of complex and expensive tests to obtain relevant data. Although the hydration test is not a routine geotechnical test, it is relatively straightforward to set up and the type of data presented in this paper should be easy to reproduce.

Typical data required by the model and that are obtained from the above two tests are shown in Table 2 . Results are given for two different backfills, a hydraulic fill, denoted as minefill A and a pastefill, denoted as minefill C. Both fills have had 3\% cement added.

Table 2 Example of data required for constitutive model for cemented hydraulic and paste fill

\begin{tabular}{lcc}
\hline Material property & Minefill A & Minefill C \\
\hline UCS $(\mathrm{kPa})$ & 422 & 380 \\
Final bulk modulus $\mathrm{K}_{\text {max-f }}(\mathrm{MPa})$ & 630 & 950 \\
$\mathrm{D}\left(\mathrm{day}^{1 / 2}\right)$ & 1.2 & 2.3 \\
$\mathrm{~T}_{0}(\mathrm{days})$ & 0.2 & 0.2 \\
$\mathrm{E}_{\mathrm{h}}\left(\mathrm{cm}^{3} / \mathrm{g}\right)$ & 0.064 & 0.018 \\
$\mathrm{c}_{\mathrm{k}}(\mathrm{m} / \mathrm{s})$ & $2.6 \times 10^{-6}$ & $5.0 \times 10^{-8}$ \\
$\mathrm{~d}_{\mathrm{k}}(-)$ & 20 & 10 \\
$\mathrm{C}^{\prime}{ }_{\max }(\mathrm{kPa})$ & 110 & 116 \\
$\Phi^{\prime}\left({ }^{\circ}\right)$ & 35 & 28
\end{tabular}

The strength parameters UCS, $\mathrm{c}^{\prime}$ and $\varphi^{\prime}$ have their usual meanings. It can be seen that the UCS for the two materials is quite similar. The pastefill is certainly not significant weaker than the hydraulic fill, although the rate of gain of strength is quite different. For example, Figure 1 shows the development of the apparent cohesion component of the shear strength for the two materials. After 50 hours of curing, there is about a two-fold difference in apparent cohesion, whereas after 200 hours the two curves are almost co-incident, with the pastefill apparently continuing to gain strength and the hydraulic fill levelling off.

Although the strength components are very similar, there are major differences between the two materials. The hydraulic conductivity of the hydraulic fill is at least two orders of magnitude greater than that of the pastefill, and the difference between them increases with hydration time as the hydraulic conductivity of the pastefill decreases by almost three orders of magnitude as a result of consolidation and cement gel growth, whereas the hydraulic fill conductivity remains virtually unchanged. The parameters ck and dk quantify the hydraulic conductivity and how it changes with time of hydration, as outlined by Helinski et al. (2007a).

The parameter $d$ represents the rate of hydration and to is the time until initial set. As indicated, this parameter is the same for both fills, namely about 4 hours. The parameter Eh is also derived from the hydration test and describes volumetric changes associated with the cement hydration process. 


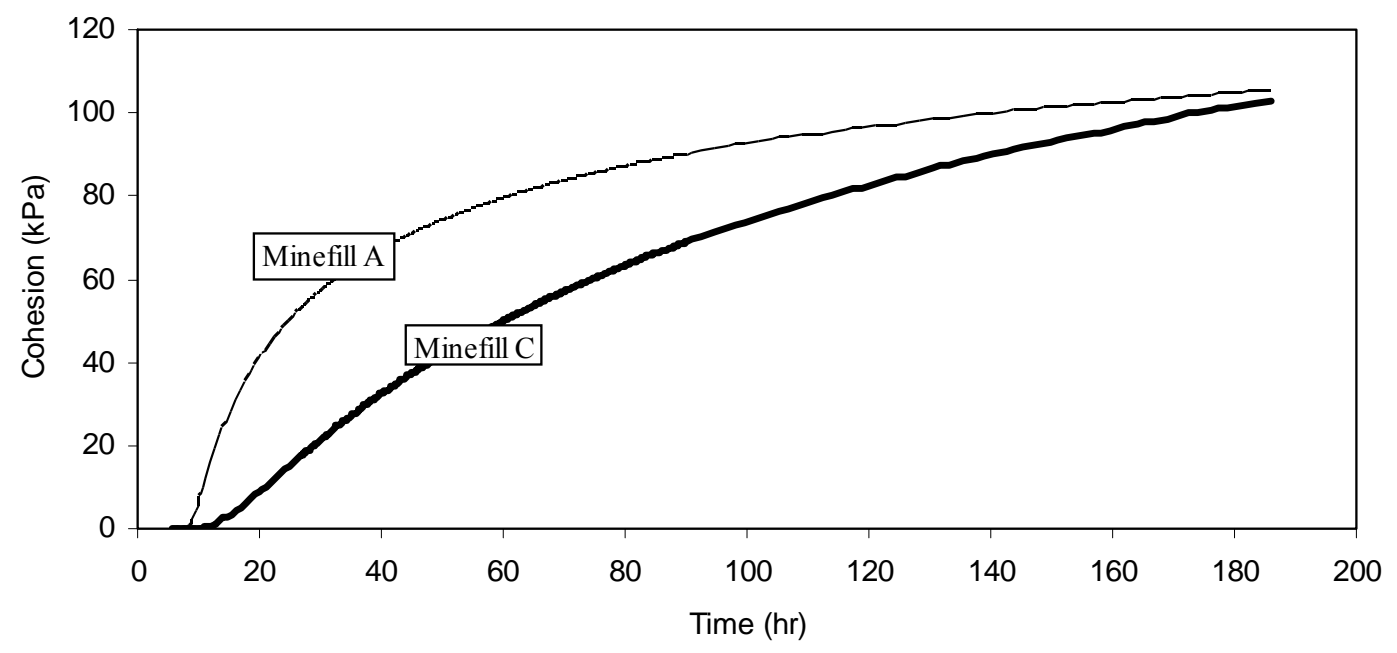

Figure 1 Development of the $c^{\prime}$ component of strength against time for two different backfill types

\section{Illustration of use of constitutive model to correctly quantify barricade loads}

To illustrate the impact of the various material properties on the filling process, the program Minefill-2D was used in plane strain mode to model the filling of a $20 \mathrm{~m}$ wide stope, $40 \mathrm{~m}$ high. A drawpoint height of $5 \mathrm{~m}$ was used, with a barricade offset distance of $5 \mathrm{~m}$. A zero pore pressure boundary condition was assigned along the barricade boundary, thus simulating fully effective drainage. The simulation was carried out for both materials, A and C, assuming a schedule of filling the first $8 \mathrm{~m}$ over a 16-hour period $(0.5 \mathrm{~m} / \mathrm{hr})$, followed by a 14-hour rest period, and then filling the remaining $42 \mathrm{~m}$ over a period of 84 hours $(0.5 \mathrm{~m} / \mathrm{hr})$. The development of pore pressure at the opposite side of the stope to the drawpoint (to minimise the distortion due to the assumed drainage boundary condition at the barricade) is shown in Figure 2.

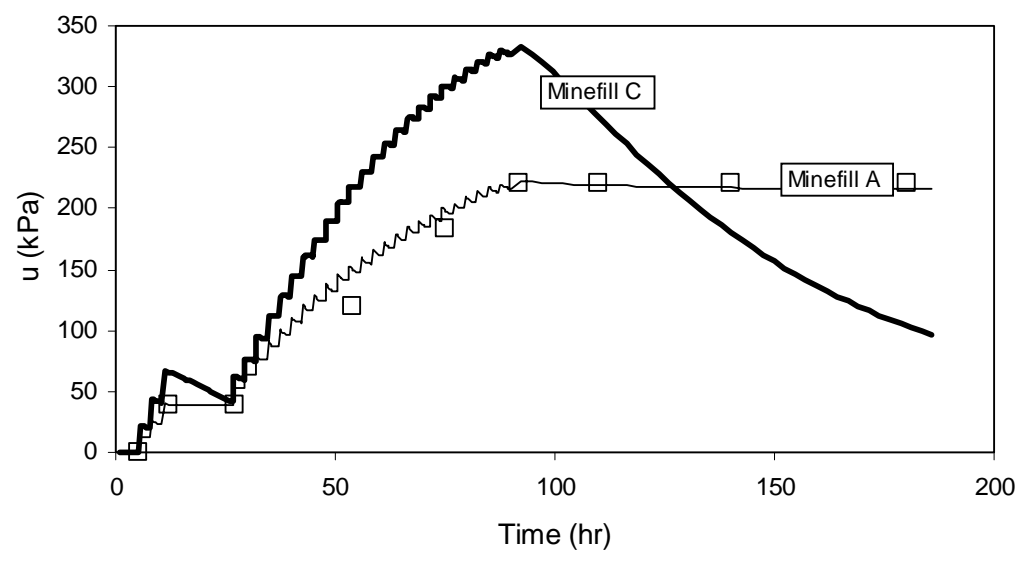

Figure 2 Development of pore pressure with time for two backfill materials

The response of the pore pressure to the rest period is clearly evident, particularly for minefill $\mathrm{C}$, where it rapidly drops from about $70 \mathrm{kPa}$ to $45 \mathrm{kPa}$. There is also a significant difference in the response of the two fill materials, with fill A reaching a lower maximum value than fill C. Bearing in mind that filling ceased at around 114 hours, the peak pore pressure in both cases occurs well before this time. For minefill $\mathrm{C}$ it begins to drop rapidly after the peak value is reached, whereas for material A, it stabilises at the peak value and then remains constant for the duration of the simulation. The pore pressures in minefill $\mathrm{A}$ in fact corresponded to steady state seepage pore pressures, which is to be expected as the hydraulic backfill has a high hydraulic 
conductivity and would drain relatively quickly. The fact that minefill $\mathrm{C}$ generates pore pressures in excess of the steady state seepage values indicates that consolidation is not complete. The corresponding maximum barricade load values for minefills $\mathrm{A}$ and $\mathrm{C}$ were $150 \mathrm{kPa}$ and $220 \mathrm{kPa}$ respectively, which is a very large difference and would not be expected based purely on the UCS values, which were very similar.

\section{Optimising fill properties through use of an appropriate testing programme and constitutive model}

The results reported in the previous section describe how barricade loads are influenced by the nature of the fill material used. This section describes how the constitutive model that has recently been developed at the University of Western Australia can be used, together with relatively straightforward testing, to optimise the backfilling process. It may, for example, be required to optimise the filling schedule (including the definition of ideal rest periods) for a given backfill blend and barricade design.

As discussed earlier, minefill $\mathrm{C}$ was a pastefill material with a high percentage of fine material. Shown in Table 1 are test results from another pastefill, this one having only about $45 \%$ finer that $75 \mu \mathrm{m}$, designated as minefill B. This material was shown by Helinski et al. (2007b) to behave rather differently from minefill C, exhibiting a much less significant decrease in hydraulic conductivity with time, probably as a result of the smaller proportion of fines and thus smaller proportion of small pores that become blocked by growth of cement gel. Predicted barricade loads are shown in Figure 3 for this material for two cases; the base condition of 3\% cement addition, and the case where only $1.5 \%$ cement was added. The base case produces low barricade stresses, of the order of $100 \mathrm{kPa}$, which was lower even than the hydraulic fill (minefill A). Reasons for this are explained in detail in Helinski et al. (2007b) and are a consequence of reduced pore pressures being generated when minefill $\mathrm{B}$ is used, due to factors such as self-desiccation induced volume changes. The primary point to be made here is the significant increase in barricade stress that occurs when the cement content is reduced to $1.5 \%$. As can be seen in Figure 3, the barricade stress increases to a peak value of over $200 \mathrm{kPa}$, which is more than twice the value obtained for the base case. Although results are not shown here, the barricade stress is also a function of the as-placed density of the backfill, and reductions are possible by ensuring the as-placed solids content is as high as possible.

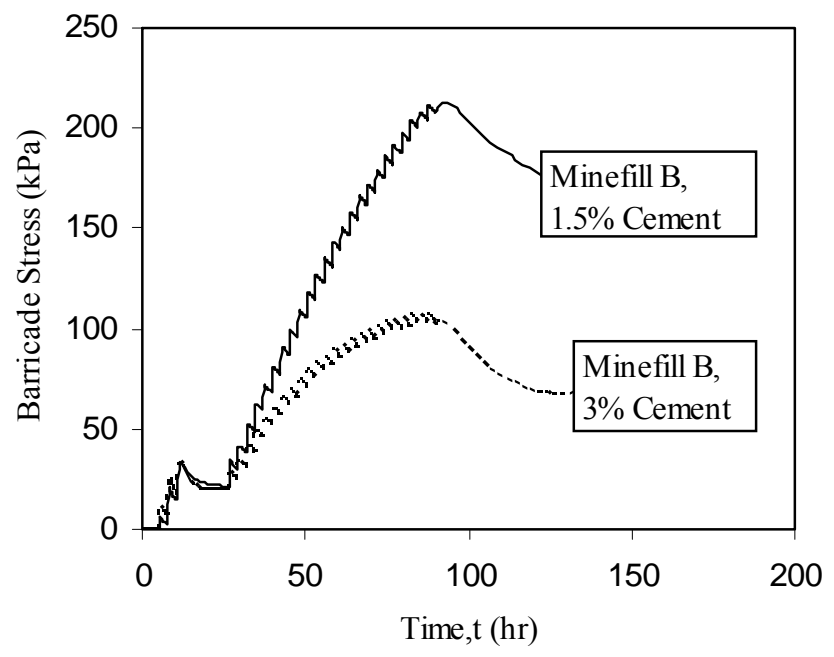

Figure 3 Illustration of effect of cement content on barricade stress, with all other parameters unchanged

\section{Relevance to a high stress environment}

The primary issue in using any type of ground support, including cemented backfill, is ensuring safety. With most other types of ground support, the safety issue arises in-service, i.e. once the system has been installed and begins to undergo loading from convergence of surrounding rock mass. With cemented backfill, the process of installation (the filling process) is a critical safety concern. As mentioned earlier, there have been 
a number of barricade failures during placement of fill, some of which have resulted in very dangerous inrushes of tailings into adjacent workings. This paper has concentrated on the development of rigorous techniques for calculating barricade loads, to ensure that safety is not compromised during the filling process. Once fill has been placed, it continues to hydrate until the ultimate shear strength is attained. When considering the use of $\mathrm{CPB}$ in a ground support application, there are other issues to be considered, as discussed below. Although we do not present results to illustrate the relevance of these issues, work in some of these fields is currently being undertaken as part of the recently established 'Minefill' research programme that has been established at UWA and ACG with industry funding. The fundamentally sound constitutive model that has already been developed provides the opportunity to tackle the issues that are raised.

\subsection{Liquefaction of cemented backfill}

It is highly unlikely that fully hydrated cemented fill, with UCS values well above $200 \mathrm{kPa}$ would be vulnerable to liquefaction under anything but the most severe dynamic loading. As the fill drains and desaturates, the susceptibility to liquefaction also decreases. Liquefaction will occur if the imposition of an external load (such as an earthquake or a mining related seismic event) causes pore pressures to rise above a certain, critical (material dependent) value. This possibility, and the risk of it occurring, can be quantified if an effective stress constitutive model (such as Minefill-2D) is utilised, because the pore pressure increment in response to load is intrinsic to the model formulation. Conventional 'total stress' models are unable to account for pore pressure development, and can only be used through the establishment of empirical, site specific correlations. Clearly this latter approach is very limited, because a number of loading events (seismic shocks) are required at a particular site to provide the necessary calibration.

If required, cyclic triaxial tests can be carried out on specimens of hydrating backfill to determine the stress level at which liquefaction might be initiated. These tests are again best interpreted in terms of effective stresses, and a constitutive model such as that discussed in this paper is an appropriate vehicle for interpretations of this type.

\subsection{Reduction of closure strains}

By minimising closure strains in an excavated stope, the likelihood of energy releases through events such as rockbursts are reduced. It is therefore the stiffness of the cemented backfill that is of primary importance in this instance, rather than the strength. The hydration test discussed in this paper is able to track the development of stiffness with time of hydration and provide a measure of when the fill reaches a particular value that may be deemed adequate to allow adjacent mining to proceed. What is still required is a technique for taking appropriate measurements in-situ that will allow quantification of the stiffness of the placed fill at any time. Work on this topic has recently been started as part of the Minefill project.

\subsection{Provision of adequate long-term shear strength}

When a stope is excavated adjacent to a previously filled stope, the exposed backfill must have sufficient strength to withstand the resulting imposed shear stresses. The evaluation of required strength is usually carried out in terms of the UCS. However, once again this does not address the fundamental behaviour of a cemented material and evaluation of available shear strength in terms of effective stresses could provide a more consistent methodology. It would require the installation of piezometers into a filled stope, to provide information on in-situ pore pressures. A related concern is the potential for degradation of strength with time, e.g. due to sulphate attack as discussed by Hassani et al. (2001). This can also be addressed using the newly developed constitutive model, as long as test data is accumulated for the required time of exposure.

Another problem that has been mentioned in the literature is that of damage to the cemented fill mass as a result of overloading, probably as a result of excessive closure displacements of adjacent excavations. The constitutive model incorporated in Minefill-2D includes the provision of a so-called 'damage' term. This facet of the model calculates damage in terms of a decrease in the available shear strength due to loading of the cemented material beyond a critical yield stress (which is determined using the two laboratory tests discussed earlier). The model is thus capable of accounting for the potential loss of the cohesive component of strength of a cemented fill, which would result in a fill that behaves as a granular material, if the adverse conditions required to initiate this problem actually occur. 


\section{Conclusions}

Cemented backfill is becoming more widely used in Australian mines. It is likely that this trend will continue, particularly the use of cemented paste backfill (CPB), in which full plant tailings, or unclassified harvested tailings are used.

Current concerns surrounding the use of $\mathrm{CPB}$, such as safety issues related to barricade stability, reliability of strength measurements and potential liquefaction, can be addressed by adopting an effective stress approach to the understanding of backfill behaviour. Only through clarifying the link between applied load and pore pressure response, which requires an effective stress model, can these issues be addressed properly. Techniques that rely on a simplistic total stress approach, which then has to be empirically corrected for each new application, cannot provide a consistent and robust approach that is necessary to ensure CPB is used with confidence in future mining applications.

Apparently anomalous behaviour, such as a drop in pore pressure while filling is taking place, have been explained using the effective stress constitutive model described in this paper. It also illustrates that a number of interconnected components of cemented fill behaviour, including stiffness gain with time, change in hydraulic conductivity due to both consolidation and gel growth, and self-desiccation, all play a crucial role in understanding the behaviour of a particular mix of tailings, binder and water. Advances in the use of CPB for improving ground support and maximising recovery are possible through an improved understanding of how this material behaves, from the time of placement, through initial hydration and until final exposure.

\section{Acknowledgements}

The work described in this paper was supported by the UWA Gledden Postgraduate Scholarships Foundation, the Shaw Memorial Postgraduate Scholarship Foundation, and MERIWA (the Minerals and Energy Research Institute of Western Australia). Continuation of the work has been made possible through the industry support provided by Barrick Gold of Australia, BHP Billiton Limited and Sally Malay Mining Limited.

\section{References}

Been, K., Brown, E.T. and Hepworth, N. (2002) Liquefaction potential of paste fill at Neves Corvo mine, Portugal. Mining Technology: IMM Transactions section A, 111(1), pp. 47-58.

Belem, T., Harvey, A., Simon, R. and Aubertin, M. (2004) Measurement and prediction of internal stresses in an underground opening during filling with cemented fill. Proceedings $5^{\text {th }}$ International Symposium on Ground Support, Villaescusa and Potvin (eds), Balkema Publishers, 28-30 September, Western Australia, pp. 619-630.

Biot, M.A. (1941) General theory of three dimensional consolidation. Journal of Applied Physics, 12, pp. $154-164$.

Coltrona, A. (2006) Material properties of cemented minefill. Final year thesis, School of Civil \& Resource Engineering, University of Western Australia, Perth, Australia.

Fahey, M. and Carter, J.P. (1993) A finite element study of the pressuremeter test in sand using a non-linear elastic plastic model. Canadian Geotechnical Journal, 30, pp. 348-362.

Fourie, A.B., Fahey, M. and Helinski, M. (2007) Using effective stress theory to characterise the behaviour of backfill. CIM Bulletin, August 2007, Vol. 100, 9 p.

Grabinsky, M.W. and Bawden, W.F. (2007) In situ measurements for geomechanical design of cemented paste backfill systems. CIM Bulletin, August 2007, Vol. 100, 10 p.

Grice, A. (1998) Stability of hydraulic backfill barricades. Proceedings Minefill '98 - Sixth International Symposium on Mining with Backfill, Brisbane, Australia, April 1998, AusIMM, pp. 117-120.

Grice, A. (2005) Introduction to hydraulic fill. Handbook on Mine Fill, Potvin, Thomas and Fourie (eds), Chapter 5, Australian Centre for Geomechanics, Perth 2005.

Hassani, F.P., Ouellet, J. and Hossein, M. (2001) Strength development in underground high-sulphate paste backfill operation. CIM Bulletin, 94, pp. 57-62.

Helinski, M., Fourie, A.B. and Fahey, M. (2006) Mechanics of early age cemented paste backfill. Proceedings $9^{\text {th }}$ International Seminar on Paste and Thickened Tailings (Paste 2006), Jewell, Lawson \& Newman (eds), Limerick, Ireland, April, Australian Centre for Geomechanics, pp. 313-322.

Helinski, M., Fourie, A.B. and Fahey, M. (2007a) The self desiccation process in cemented mine backfill. Accepted for publication, Canadian Geotechnical Journal.

Helinski, M., Fahey, M. and Fourie, A.B. (2007b) An effective stress approach to modelling mine backfilling. CIM Bulletin, August 2007, Vol. 100, 10 p. 
Marston, A. (1930) The theory of external loads on closed conduits in the light of latest experiments. Bulletin No. 96, Iowa Engineering Experiment Station, Ames, Iowa.

Potvin, Y. and Fourie, A.B. (2005) Paste fill in Australia. Symposium 2005 on Mines + Environment, Rouyn, QC, May 2005, pp. 16-18.

Rankine, R.M., Rankine, K.J., Sivakugan, N., Karunasena, W. and Bloss, M. (2001) A numerical analysis of the arching mechanism in pastefill throughout a complete mining sequence. Proceedings $1^{\text {st }}$ Asian Pacific Congress on Computational Mechanics, Sydney, pp. 461-466.

Terzaghi, K. (1943) Theoretical soil mechanics. John Wiley and Sons, New York.

Yumlu, M. and Guresci, M. (2007) Paste backfill bulkhead failures and pressure monitoring at Cayeli Mine. CIM Bulletin, August 2007, Vol. 100, 10 p. 